\title{
Los jóvenes en los márgenes y su sentido moral de la historia'
}

\author{
Young people on the margins and their \\ moral sense about history
}

\begin{abstract}
Alexander Ruiz Silva²
Resumen

Este trabajo se inscribe en el encuentro de enfoques y teorías de los campos de la filosofía práctica y la investigación en enseñanza y aprendizaje de la historia. Se exponen y analizan relatos de jóvenes argentinos, de un contexto social marginal, sobre su nación del presente y sobre la relación entre la historia vivida (cotidiana) y la historia aprendida (historia escolar-disciplinar). El análisis indica, entre otras cosas, una construcción narrativa defensiva de la nación, en la que los jóvenes no establecen mayores vínculos con su propio pasado o con sus proyecciones futuras, de modo tal que la nación en los márgenes pareciera sostenerse en una tensión entre ilusión e incertidumbre. Cuanto más se amplía el espectro de lo segundo, más parece reducirse el de lo primero

\section{Palabras clave}

Historia nacional, nación vivida, sentimientos morales, usos de la historia

\section{Abstract}

This paper is part of a blend of approaches and theories from practical philosophy and teaching and learning research related to history. It highlights and analyses stories of Argentine youth from a marginal social context about their current nation and the relation between a lived (daily) history and a learned (academic-disciplinary) history. The analysis indic ates, among other things, a defensive narrative construction of a nation where young people do not have a close link to their own past or future projections, so much so that nation borders seem to be in tension between illusion and uncertainty. The more the spectrum of the latter is amplified, the more the first seems to be reduced.
\end{abstract}

Key words

National history, lived history, moral feelings, uses of history.

Artículo recibido el 28 de marzo de 2012 y aprobado el 19 de julio de 2012

1 El presente artículo retoma asuntos tratados en mi tesis doctoral: La nación en los márgenes. Estudio de los elementos de carácter representacional, moral y político en relatos de nación de jóvenes de últimos grados de secundaria, de una escuela pública, en el conurbano bonaerense, del programa de Doctorado en Ciencias Sociales de la Flacso -Argentina- 2009. También se establece un diálogo con algunas consideraciones de carácter analítico incluidas en la tercera parte de mi libro: Nación, moral y narración (Buenos Aires, Miño y Dávila, 2011). No obstante, la mayor parte del contenido del texto se encontraba hasta ahora inédito, incluyendo las representaciones gráficas de la nación del último acápite.

2 Profesor titular de la Universidad Pedagógica Nacional, Bogotá, Colombia. Correo electrónico: aruiz@pedagogica.edu.co 


\section{Hacia una lectura moral de la historia}

Partimos aquí del supuesto de que toda interpretación histórica se encuentra moralmente articulada y que ninguna concepción de acontecimiento, hecho, evento o sujeto histórico se construye, significa o relata de manera neutral (Todorov, 1991; Ricoeur, 2000; White, 2003). De este modo, el papel de la esfera moral en la enseñanza de la historia ha sido objeto de reflexión por parte de algunos teóricos de distintas disciplinas y ámbitos de las ciencias sociales (Todorov, 1995; Von Borries, 1994; Rüsen, 1999, 2005; Ricoeur, 2000). Sin embargo, escasean los estudios empíricos que toman a dicha esfera como centro del análisis. En el texto de Barton y Levstik (2004, pp. 91-109) se citan algunas experiencias de investigación llevadas a cabo en escuelas de Irlanda del Norte y de los Estados Unidos, en las que se analiza el papel de las reacciones morales ante el aprendizaje de eventos históricos de diversa índole. Estos autores destacan que procesos como la remembranza y el olvido (o lo recordable y lo olvidable), las percepciones de justicia y equidad, la definición del héroe y lo heroico, son elementos morales prácticamente ineludibles en "nuestro encuentro con el pasado". Una más clara conciencia sobre los mismos podría contribuir -según concluyen- a una mayor empatía con las víctimas de la historia, así como a la preparación de los niños y adolescentes en la deliberación sobre la justicia en la vida pública hoy.

Kenneth Gergen (2005), por su parte, analiza la relación entre narración, conciencia histórica y construcción de identidad moral. Para este autor, la narración histórica funciona fundamentalmente para crear, sostener y posiblemente desbaratar o transformar tradiciones de valores. Gergen enfatiza que la conciencia histórica es inherentemente conciencia narrativa, en la medida en que estamos orientados a una dirección en la cual la realidad conversacional creada por el relato histórico cumple una función dentro de la cultura: servir de constructor o sostenedor de una tradición cultural e investirla de valor y racionalidad para el futuro. "En efecto, la narración histórica está inevitablemente conectada a valores culturales y a la moralidad. Confiere inteligibilidad a determinada tradición y afirma de manera silenciosa el sentido de lo bueno que ella encarna”. (Gergen, 2005, p. 116).

El tema de la moral en la comprensión de la historia ha estado presente también en diversos trabajos empíricos de Peter Seixas. Este investigador subraya que en los juicios morales que se hacen sobre actores históricos se corre constantemente el riesgo del anacronismo, dado que solemos imponer nuestros propios criterios morales a personas en circunstancias y con mentalidades muy diferentes a las nuestras: "Únicamente teniendo en cuenta las amplias diferencias producidas por el cambio histórico podemos rebasar los juicios sobre el pasado" (Seixas, 2005, p. 144). Sin embargo, destaca igualmente, "el conocimiento histórico que no es guiado por una orientación moral o por juicios morales es históricamente inútil: porque, cómo podríamos comprometernos con un proyecto histórico para todos si no podemos nosotros mismos otorgarle una orientación moral" (Ibíd., p. 144).

En un estudio sobre la comprensión de la historia ligada a la celebración de actos patrios (efemérides) en escuelas argentinas, Carretero destaca la presencia central de aspectos morales que opacan o subordinan otros de tipo político, haciendo que los agentes históricos queden reducidos a simples individuos a quienes la historia les determina externamente un rol: "Los actores sociales aparecen como pasivos en tanto desempeñan eficazmente el papel que la historia (activa) les determina. Tales explicaciones morales parecen obstaculizar la comprensión disciplinar de la historia, la incorporación del conflicto como fuente activa de ésta y la integración de identidades diferentes en las narraciones históricas." (Carretero, 2007, p. 279). Aquí la adhesión emotiva a la nación pareciera promover una respuesta heterónoma en el estudiante y facilitar la naturalización de relaciones sociales desiguales.

En consonancia con este hallazgo, la investigación de Miriam Kriger sobre representaciones de jóvenes argentinos sobre el pasado, presente y futuro de la nación, con estudiantes de primer semestre de distintas carreras de la Universidad de Buenos Aires (CBC: ciclo básico común), detectó elementos de 
carácter moralista que obstruían cualquier tipo de conflicto cognitivo en la comprensión de la historia, especialmente en relación con la naturalización de la violencia. Tales elementos "irrumpen literalmente desde el presente y los conflictos actuales [...]. Notamos asimismo que cuanto más radical es el conflicto normativo y falsamente moral, mayores son también los dispositivos de negación de la violencia, hasta que la reivindicación se vuelve fallida -invirtiéndose de acuerdo a lo que aquí llamamos "la pirueta moralista" - y termina por disolver la propia legitimidad histórica de las identidades políticas a reivindicar." (Kriger, 2007, p. 411).

En un estudio sobre la manera como los nuevos patrones de inmigración en los Estados Unidos pueden jugar un importante rol en la enseñanza de la historia en la escuela pública, VanSledright (2008) encuentra que la historia que se enseña en los salones de clase autoriza y promulga una narrativa de desarrollo y progreso de la nación, constituida como visión que debe ser preservada, reproducida y sostenida en el tiempo. En consecuencia, señala el investigador, la construcción de la memoria colectiva sobre la formación de la nación se orienta fundamentalmente a la construcción de una identidad cultural. Las clases de historia en las escuela públicas de Estados Unidos abundan en prescripciones que moldean y marcan una narrativa triunfal de la nación que sirve a un poderoso propósito sociocultural: "Provee los elementos necesarios para asegurar la lealtad de las personas al Estado-nación" (VanSledright, (2008, p. 137)

Estos estudios plantean la necesidad de una exploración más detallada del papel de lo moral en la comprensión de historia en la escuela. Lo que interesa aquí, entonces, es dar cuenta del modo mediante el cual el aprendizaje de la historia y su relación con las historias particulares de sujetos en condiciones de exclusión y marginalidad moldean ideas, imágenes y proyecciones de nación.

\section{Sobre actores, preguntas y persuasiones}

Cada vez es más alto el porcentaje de la población en América Latina orillada a vivir en condiciones de pobreza extrema, razón por la cual se considera aquí que los imaginarios y vivencias de nación requieren ser estudiados y analizados en tales condiciones y contextos, en tanto se asume que estas reflejan, en buena medida, formas relevantes de ser y habitar el mundo, modos de construir o reproducir apuestas políticas y de hacer proyecciones de sociedad.

Así, el trabajo de campo de este estudio se llevó a cabo en una escuela pública de un sector marginal del conurbano bonaerense (municipio de San Francisco Solano, al sur de Quilmes) entre el 2007 y el 2008. La elección del sector y de sus participantes no fue, en absoluto, azarosa. Se trató de analizar lo que tienen de particular las vivencias, creencias e imaginarios de nación en la periferia de la periferia, esto es, en la periferia político-geográfica de la ciudad de Buenos Aires y en la periferia del modelo de desarrollo económico imperante.

La pregunta principal que orientó nuestro análisis fue: ¿qué tipo de relaciones éticas y políticas establecen los estudiantes entre su propia historia - personal y contextal- y la historia aprendida de su nación? Lo cual nos llevó a reparar en la utilidad simbólica o práctica que le atribuyen los jóvenes de últimos grados de secundaria a la historia escolar aprendida, en el modo en que este tipo de aprendizaje y su propio pasado vivido se tensionan o complementan en sus relatos del nosotros nación. Esto fue posible a partir del análisis de los relatos de los jóvenes, producidos mediante entrevistas informales y semiestructuradas, diarios de campo y talleres de aula orientados a la producción de "relatos gráficos" sobre su propia nación.

Se trató de indagar la manera como el aprendizaje del pasado y el pasado vivido se dotan de significado. Dotar el pasado de significado quiere decir, entre otras cosas, dar una orientación moral específica a cada interpretación e intentar hacer prevalecer dicha orientación. Sobre este particular, Jörn Rüsen (2001, pp. 154-155) señala que la narración -o como él prefiere denominarla: la articulación narrativa- posee una innegable capacidad realizativa, en tanto permite que se formulen en el presente juicios morales sobre cosas ocurridas en el pasado. De este modo, ningún relato histórico es valorativamente neutral, e incluso la búsqueda o 
expresión de imparcialidad comportaría, en sí misma, una postura moral y una recursividad retórica, tal y como ocurre con los relatos de cualquier otra índole en la vida de los seres humanos. En palabras de Ricoeur: "La estrategia de persuasión fomentada por el narrador tiende a imponer al lector una visión del mundo que no es nunca éticamente neutra, sino que más bien induce, implícita o explícitamente, una nueva valoración de mundo y del propio lector: en este sentido, el relato pertenece ya al campo ético en virtud de la pretensión de lealtad ética, inseparable de la narración." (Ricoeur, 2003, pp. 1001-1002).

\section{Los usos de la historia aprendida}

Qué tanto sabemos sobre el uso que le damos a las cosas que hemos aprendido es algo difícil de responder, incluso, cuando intentamos hacer conciencia de ello. Los contenidos de historia que son objeto de recordación formal en la escuela, de rememoración y conmemoración, y la historia de vida de cada quien suponen relaciones de las que, igualmente, es difícil dar cuenta ${ }^{1}$. En todo caso, ello involucra una habilidad metacognitiva: la capacidad de reflexionar y precisar la naturaleza y límites del saber adquirido y la manera como se utiliza el mismo. Veamos la utilidad simbólica o práctica que los jóvenes atribuyen a la historia aprendida. Vale aclarar que la voz "utilidad" se usa aquí de forma laxa. Esto, que podría considerarse una limitación del estudio, permitió que fuesen los jóvenes mismos quienes le otorgasen significado a este término, en relación con su cotidianidad y el contexto en el que ella discurre. El siguiente cuadro organiza las

1 Para una mayor comprensión de los conceptos de rememoración y conmemoración seguimos la perspectiva de Ricoeur, para quien el acto de conmemoración se sitúa en el binomio memoria-hábito / memoria-recuerdo, así: “Las conmemoraciones son tipos de rememoraciones, en el sentido de reactualización, de los acontecimientos fundadores sostenidos por la "Ilamada" a acordarse que solemniza la ceremonia [...] Es cierto que no hay que limitar los actos de conmemoración a las celebraciones religiosas y patrióticas; los elogios y los servicios funerarios son también celebraciones; yo diría que se desarrollan en el tiempo de los allegados, de los próximos, a mitad de camino de la memoria privada y de la social [...] Siempre que pronunciamos o escribimos la frase "en memoria de..." inscribimos el nombre de aquellos de los que hacemos memoria en el gran libro del co-recuerdo, el cual se inscribe a su vez en un tiempo más largo" (Ricoeur, 2003, pp. 66-67). respuestas de los chicos a esta cuestión y los relatos que siguen presentan algunos matices en los que vale la pena detenerse:

Tabla 1. Creencia en la influencia o no de la historia de la nación propia en la historia personal.

\begin{tabular}{|c|c|c|}
\hline Cree que: & Parámetro & \\
\hline \multirow{2}{*}{ Sí influye } & Frecuencia & 35 \\
\hline \multirow{2}{*}{ No influye } & Porcentaje & $70 \%$ \\
\hline & Frecuencia & 15 \\
\hline
\end{tabular}

Entre los fragmentos de relatos que reconocen influencia de la historia de la nación propia en la historia personal se encuentran las siguientes:

Entrevistador (E): ¿Crees que la historia de tu nación influye de alguna manera en el curso de tu vida?

Johana: Y sí, en la identidad, digamos, porque yo tengo muchas costumbres que son de Argentina, porque mis papás vienen del campo, de Tucumán, todo eso. Y sí, porque somos bien argentinos, en la cultura, digamos.

Isaac: Puede ser, porque a través del tiempo y de todo lo que se vivió en la Argentina, la dictadura, como que ahora la sociedad me permite hacer muchas cosas que por ahí antes no se podían.

Maximiliano: Yo creo que siempre influyó, desde que nací hasta ahora. Yo creo que en el tema económico, por las cosas que se hacen mal, desde Menem hasta el que está ahora. Yo nací en el 89 cuando había asumido Menem, pero todo lo que hizo al vender todas las empresas del Estado, se produjo un aumento en la tasa de desocupación, eso produjo que el país cayera un poco. Y, bueno, después vino De la Rúa que hizo estragos, toda esa historia me influye.

Andrea: Claro, lo que acá se perdió es mucha confianza. Nosotros, por ejemplo, confiábamos mucho en el presidente, en los gobernantes. El tema del cacerolazo a mí me llegó mucho, me pegó mucho. Y ahora es como que ya después del corralito se perdió todo, ya nadie confía en nadie, ni en uno mismo, creo. 
En muchos casos fue necesario formular esta pregunta de otro modo: ¿crees que la historia de la Argentina ha influido en tu historia personal y en el tipo de vida que llevas?

Federico: Sí, yo creo que sí, porque una vez que estudiaste o leíste o escuchaste capaz que algo se te queda. Uno aprende a no ser tan injusto, a no querer más de lo que tenés: ganalo, no busqués que el otro pierda algo para que vos ganés, ganalo por tu parte.

Como podemos ver, estos jóvenes contemplan algún tipo de influencia de la historia de su nación en sus propias historias personales y tal influencia es reconocida en elementos culturales e identitarios; en la necesidad de comprender el presente y tomar algunas previsiones mínimas para el futuro; en la valoración favorable de conquistas sociales, derechos y libertades individuales; en la conciencia de vivir en condición de desventaja, producto de una iniquidad históricamente constituida en la nación; $y$, finalmente, en el deseo de aprovechar lo aprendido como consigna moral para orientarse en el desarrollo de iniciativas individuales.

Los relatos vislumbran elementos de orden pragmático: descenso en la calidad de la educación recibida y en el acceso a derechos formales; y otros de carácter existencial: pérdida de confianza generalizada y adquisición de aprendizajes para la vida. Aquí la historia es reducida a simple pasado, esto es, los hechos acaecidos y experimentados por los mismos estudiantes, por las generaciones que les anteceden o por la sociedad, especialmente aquellos hechos reconocidos como hitos del pasado reciente. En ningún caso se alude a la historia en términos disciplinares o académicos. Esta idea de la historia como pasado vivido y no como pasado reflexionado sistemáticamente, o cernido en el tamiz de herramientas conceptuales, no es muy distinta entre quienes le niegan a la historia de la nación influencia alguna en su propia historia personal. Veamos:

Leonardo: En mí, por lo menos, no; en otros, no sé. Digamos que yo no me fijo en esas cosas, yo soy un chico que mira muy poco noticieros, yo vivo la vida así nomás. Yo me levanto y hago lo que tengo que hacer. A mí mucho no me influye porque no soy un chico que está muy relacionado con el tema.
Daniel: No influye porque yo sinceramente no me siento argentino, no le encuentro significado a sentirse argentino.

Jonathan: En mi vida no creo que influya mucho, pero sí en la de mis familiares. Se marcó mucho en ellos, pero no en mí, porque yo soy de otra generación y no ha pasado nada importante en Argentina en esta generación.

José: La historia de la Argentina es muy distinta a lo que vivo ahora, pienso que es muy distinto; a pesar de que esas cosas hayan quedado en la memoria, no por eso voy a decir que lo voy a vivir, ahora tengo otra vida, Argentina tiene otra vida.

Quizás la diferencia central de estos relatos, con relación a los anteriores, es que para estos jóvenes no haber jugado un rol directo en los hechos del pasado, no haber sido testigos de excepción o no haber tenido que asumir responsabilidades concretas ante las circunstancias mencionadas, los deja por fuera de la influencia de la historia o, al menos, por fuera de su influencia directa. Vale la pena remarcar que terminar la escuela secundaria es para estos jóvenes un ritual de paso hacia nuevas o adicionales responsabilidades, es hacerse adulto prematuramente, cursar una carrera corta, convertirse en sujetos económicamente productivos. Este paso es concebido como el momento de la verdad, en el que muchos de ellos se hacen cargo de otros (padres, abuelos, hermanos menores) y pueden ya empezar a "vivir plenamente" los efectos de la historia.

La interacción permanente con estos chicos nos permitió establecer que muy pocos deciden cursar una carrera universitaria, la mayoría debe atender las urgencias que demanda el contexto. De este modo, hacer una carrera corta es la alternativa por la que optan, en igual número, hombres y mujeres, casi que en función exclusiva de atenuar las dificultades del presente. ¿Es este un indicador de renuncia a la promesa que dotó de sentido la escuela Argentina y latinoamericana de generaciones anteriores y mediante la cual se vinculaba la aspiración a la formación universitaria con la movilidad social? ¿Es simple y llano realismo de parte de los jóvenes? ¿O quizás ambas cosas?

"Ganalo por tu parte" decía Federico, más arriba, luego de afirmar que la historia le enseña a ser menos 
injusto. Lo que hace a esta declaración excepcional en este contexto no es solo la positividad de la consigna moral a la que apela, sino, principalmente, la idea de usar lo aprendido para orientar su propia acción, para participar en la delineación de un futuro que luego será historia o pasado vivido activamente. Esta excepcionalidad confirma la regla, evidencia la forma en que estos jóvenes se perciben a sí mismos como herederos del pasado, no como constructores de historia.

De otro lado, la pregunta por la influencia de los conocimientos sobre la historia de la nación propia en el futuro personal permite develar otros matices de la relación en cuestión. Veamos:

Entrevistador (E): ¿Crees que lo que aprendiste, lo que sabes sobre la historia de tu nación puede influir en tu futuro?

Carlos: Y sí, por ejemplo, yo ahora no sé nada de mi país y en mi futuro me va a afectar, ya me está afectando, de lo que vos me preguntás casi no sé nada.

Anabel: Y sí, porque ojalá dios quiera que no haya una guerra, pero si hay una guerra yo haría lo mismo que mi viejo, mi viejo es excombatiente de Malvinas. Yo estaría en la misma situación de él y haría lo miso que él, es lo que yo haría.

Nancy B.: Y creo que sí, que es importante saber, para comentarle a los hijos vendría a ser.

Nancy: Sí, porque algunas cosas que fueron sucediendo son para que la sociedad aprenda a defenderse; por eso hoy hacemos respetar los derechos, bueno, algunos hacen respetar sus derechos, o sea, antes se reprimía todo y se sentía miedo al poder, al que estaba a cargo, hoy no.

Sandra: Y sí, si valorás un poco más las cosas, vas a ir manejándote mejor y a pensar en lo que hicieron los demás. Las cosas malas y las cosas buenas que pasaron todo implica en tu futuro. Yo pienso que los argentinos no son tan tontos de otra vez cometer los mismos errores, los errores se cometen una vez, creo que dos no.

Jessica: Sí, supongo. Todo pasado siempre vuelve como futuro. Yo creo eso, yo creo que las cosas que se hacen en un momento por ahí después siguen pasando con el tiempo, por ahí uno no se da cuenta, todas las macanas, todas las cosas que se pueden llegar a hacer mal después, en un futuro no muy lejano, traen consecuencias, creo eso.

La ausencia de conocimiento sobre la historia de su propia nación desde ya está marcando la vida de algunos de estos jóvenes: un sentido de solidaridad con el padre parecería guiar las decisiones de una de las estudiantes ante eventuales guerras venideras, esto es, la asunción de un destino compartido; la idea de ser previsivos a partir de las señales que permite detectar la experiencia se destaca en otros relatos; enterar de las cosas sucedidas a las nuevas generaciones es también una utilidad percibida; la confianza en el aprendizaje de la sociedad de los errores del pasado es lo que esperan algunos de ellos, mientras que, en particular, para Jessica parece haber una conexión intrínseca entre pasado y futuro, unido, según su punto de vista, a una falta de conciencia sobre cómo el primero suele reiterarse en el segundo.

Esta intuición de Jessica y el sentido práctico y, por supuesto, controvertible de todas las posturas mencionadas, indican una gran potencialidad para la enseñanza de la historia en la escuela, al menos en este rango de edad (16-19 años), y una valoración positiva de este tipo de conocimiento como herramienta para la comprensión de las propias circunstancias de vida y del curso de la sociedad nacional en la que se vive y de la que se hace parte. Pero, por otro lado, la conciencia de la exclusión padecida, la exclusión real y concreta que se reproduce y pareciera perpetuarse en la vida de estos jóvenes, marginaliza sus propias historias y proyectos, los hace invisibles, los fija en el puro presente:

José: La historia de la Argentina no influye en mi vida, creo que no. No tiene nada que ver con lo que voy a hacer cuando me reciba; por ejemplo, si vos estudias técnico electrónico no hace falta que sepas la historia de la Argentina. No, creo que no.

Emely: No, creo que no. Pienso que si no influye ahora, en el futuro tampoco, no me sirve para nada.

Isaac: No. El pasado pisado, volver al pasado me parece estúpido, reflexionar sobre el pasado es algo que no sirve para nada, aquí seguimos siempre igual. 
Johana: Yo creo que no, mi futuro depende de mí misma, de nada más.

Rodolfo: No influye ni en mis deseos, en nada.

La experiencia de todos los días de estos jóvenes trae sus propias urgencias, las mismas que en la mayoría de los casos suspenden, aplazan u obstruyen sus intereses académicos, posibilidades de ascenso social y aspiraciones vitales. La siguiente descripción densa permite ampliar la comprensión de aquello que está siendo obturado, esto es, la posibilidad de un auténtico reconocimiento, vinculada a una relación posible y cierta con el conocimiento:

Recuadro 1. Diálogo con Gabriel.

\section{A pocos kilómetros de Buenos Aires y muy lejos de la Argentina}

Gabriel: Trabajo en una pescadería. Yo me levanto tres y media de la mañana, entro cuatro y diez, cuatro y cuarto, me esperan los camiones que llegan de Mar del Plata a descargar la mercadería. Y, de ahí, cada uno tiene un puesto en la calle y entonces hay que cargarlo, limpiar todo, dejarlo en buenas condiciones y después a salir a vender. Es como un negocio ambulante.

Entrevistador: ¿En qué sector trabajas?

G: Y, acá en Solano y después en Quilmes, por todos lados, en Solano la mayoría de las veces. Mi negocio está hasta más o menos una y media de la tarde. Y después viene el camión, los engancha, los lleva y los guarda de vuelta. Y así sucesivamente de martes a sábado. Se cansa mucho el cuerpo en bajar, subir todo el pescado.

E: ¿A la una y media te desocupas y te vienes para la escuela?

G: Sí, a veces sí, cuando llego, sí. Si trabajo hasta tarde ya no llego, no hago tiempo en ir y volver, cambiarme. Y, otra, que lo tengo que hacer porque mi mamá perdió el trabajo y yo tengo que pagar el alquiler, los impuestos, todas esas cosas. Entonces, como que ya tengo que empezar a ayudar, o sea, no es que ayudo porque yo quiero, es que así vino la mano. O sea, mi mamá nunca tuvo un trabajo fijo, siempre anduvo que un año trabajaba en un lado, otro año trabajaba en otro, $y$ así. Somos solo ella y yo, desde que me abandonó mi papá a los cinco años y ahí empezamos a luchar los dos juntos.

Siempre, o sea, siempre anduvimos alquilando en algún lado, de un familiar, un conocido, como que nunca me sentí bien por eso. Cuando yo voy a la casa de alguien no me siento cómodo, como que me siento observado, lo que hacés, lo que dejás de hacer, no me siento.

Estamos alquilando una casa. Hace poquito que también nos mudamos, estábamos en otra donde el terreno ese, según, lo iban a vender, pero era todo mentira, era para que nos fuéramos y poner a otra gente. Me cuida mucho mamá, si me llego a perder o yo la pierdo a ella no sé quién termina peor de los dos, por las cosas, ¿no?, que pasan hoy en día en la calle. Con lo que gano mantengo la casa, por eso es que a veces no puedo venir a la escuela

E: ¿Qué piensas hacer cuando termines la escuela?

G: Y, si tengo la oportunidad de seguir ahí, voy a seguir ahí en ese trabajo. Tendría más responsabilidad y también podría dormir más. Lo que pasa es que son pocas horas que se duerme, solamente cuando llegan los domingos puedo. Domingo y lunes, donde se descansa más.

E: ¿Qué haces cuando no estás en el trabajo o en la escuela?

G: Descanso porque el baile no me gusta mucho. Lo que pasa es que, hoy en día, si salís a bailar, creo que salís peleándote. Por nada, porque te miraron mal, porque estás de la forma que no tenés que estar vestido, todas esas cosas. Por la discriminación que hay. Por ahí vos lo mirás y ahí empieza una pelea, por una mirada no más o por un choque, lo golpeaste sin querer y ya salís peleando. Hasta te pueden matar por nada.

Hoy en día, a mí, para entrar, no sé, de basurero, tenés que tener secundario completo. Antes, solo te probaban y ya trabajabas, ya tenías tu sueldo, ahora, como que te alargan el camino para conseguir un trabajo. Y otra cosa es que antes no te faltaba un plato de comida, y hoy en día se 
ve a simple vista en las calles. Yo lo viví también porque tuve que salir a pedir.

E: ¿Cuando eras más chico?

G: Sí, a los doce años, por ahí. Vivíamos con mi abuela, mi mamá trabajó en una casa, después perdió ese trabajo, se fundió, o sea, la patrona no le pudo pagar más. Bueno, después, de ahí, mi abuela nos echó de su casa -o sea, vendría a ser la mamá de mi mamá-, nos echó y nos fuimos casi llegando a Varela, donde eran todos asentamientos. Y, bueno, ahí vivíamos con una familia y ahí empezamos a ir a Capital. Íbamos en tren, desde la estación de Varela hasta Constitución y ahí empezábamos a caminar, a buscar en los tachos de basura, todas esas cosas.

Y caminaba, de Constitución me iba hasta Once o Retiro, caminaba en toda esa zona, Congreso, todas las partes de Capital Federal, pidiendo, así, en las casas de comida, panaderías, todo. Y donde la gente ya te veía y te conocía y te daba. Pero después, cuando empezó a haber más, más y más gente pidiendo, ya como que perdiste esa zona. Era como que vivíamos a unos kilómetros de Buenos Aires, pero lejos de todo, de la Argentina vendría a ser.

E: ¿Cómo imaginas que va a ser tu vida en adelante?

G: Si le digo, le miento; la verdad, no sé. Pero con tener lo necesario: una casa, una vivienda y un plato de comida, creo que ya basta, y la paz sobre todo. Creo que con eso uno vive.

A mí me duele ver a un chico que ande pidiendo, porque sé lo que es eso, los que están en la calle, todas esas cosas. O quizás siempre hay que tener una infancia dura para seguir el resto de tu vida, o sea, desde muy chico me tocó vivir creo que lo más malo, nunca una parte buena, siempre el lado difícil. No sé si... bueno, mala persona no soy, creo que no le hice mal a nadie. Siempre traté de dar lo mejor que pude, no sé, yo soy como soy.

La utilidad simbólica y práctica que los jóvenes le atribuyen a la historia aprendida en la escuela depende no solo de lo declarado en el presente, en sus relatos, sino también de la conciencia de lo que pueden hacer o no con ello en el futuro: "Reflexionar sobre el pasado es algo que no sirve para nada, aquí seguimos siempre igual" enfatiza Isaac; "No influye ni en mis deseos", nos dice Rodolfo. Al tiempo que las estrategias de supervivencia de jóvenes como Gabriel agotan su eficacia ante la eminencia del cambio de roles al terminar la escuela y les enfrenta a poderosos obstáculos, la mayoría de las veces invisibles. Así, la historia aprendida se torna pasado reproducido y amenaza con reducirse solo a ello.

La historia cotidiana, el pasado personal es aquí la historia de la no agencialidad, vivencia de los efectos particularmente negativos de aquello que está siendo determinado por otros. Para los jóvenes que terminan hoy la escuela secundaria en Solano, en cualquier sector marginal del conurbano bonaerense, en tantos otros lugares de la Argentina o de América Latina, y que viven una enorme incertidumbre ante un futuro ligado a la precarización del empleo y a la creciente restricción de oportunidades de acceso a la educación superior, la historia, la nación y la historia de la nación son abstracciones muy distantes de la experiencia de todos los días. En franco abandono de propósitos societales, la actual versión del Estadonación mínimo reduce la adscripción nacional al nacimiento o permanencia de las personas en un determinado territorio y a su vinculación afectiva con símbolos y relatos patrios autocelebratorios, pero a la vez desprovistos de metas comunes o de alguna idea de proyecto compartido.

\section{La esquiva nación}

El modelo económico vigente promueve en el sujeto que transita los márgenes de la nación y de su historia, es decir, en el ciudadano nominal, la capacidad de optar por las prácticas sociales que mejor se acomoden a sus preferencias. Este, se supone, es libre de elegir qué consume y qué no, de acuerdo con sus propias posibilidades. Quienes mayormente se encuentran desposeídos de capital económico y cultural tienen claramente restringida esta "libertad" y como alternativa podrán recurrir a prácticas sociales residuales, a formas locales de ejercicio de la solidaridad. 
La sociedad de consumo realmente carece de nación. Se materializa, cuando mucho, en territorios de consumo. Para Svampa (2005), en los países periféricos, al imponerse un esquema de crecimiento económico disociado del bienestar del conjunto de la sociedad -lo que ella denomina sociedad excluyente- se produce, a la vez, modernización económica y polarización social, esto es, un abandono de cualquier tipo de referente identitario que desemboque en acciones de mejora de las condiciones de vida de los más afectados por dicho esquema.

La actual situación social de la región señala una progresiva pérdida de lazos sociales comunales, supremacía de un individualismo cerrado desde el cual se construyen proyectos de vida casi exclusivamente movidos por anhelos de autorrealización, autosuperación o supervivencia, con escasa o nula apelación a proyectos compartidos.

La sociedad contemporánea exige que los individuos se hagan cargo de sí mismos y que, independientemente de sus recursos materiales y simbólicos, desarrollen los soportes y las competencias necesarias para garantizar su acceso a los bienes sociales [...] a diferencia de los países del centro, altamente desarrollados -en donde los dispositivos de control público y los mecanismos de regulación social suelen ser más sólidos, y los márgenes de acción política, más amplios-, en las sociedades del capitalismo periférico tradicionalmente las dificultades de "devenir-individuo" han sido mayores, con lo cual la implantación de un nuevo orden liberal profundizó los procesos de marginalidad y desintegración social preexistentes, multiplicando las desigualdades y las formas de la pobreza. [...] El proceso de desregulación e individualización no sólo significó el declive y la fragmentación (política y social) de la ciudadanía, sino también la legitimación generalizada de los modelos de ciudadanía restringidos, que no poseen un alcance universalista ni aspiraciones igualitarias. Antes bien, estos modelos establecen las nuevas condiciones de acceso a bienes y servicios sociales básicos dentro de la lógica del mercado, el nuevo escenario confronta a los individuos con la exigencia de tener que procurarse el acceso a ciertos bienes y servicios básicos, que antes estaban total o parcialmente garantizados por el Estado, sin que en esta redefinición del contrato social importen los recursos y capacidades, materiales y simbólicos, con que cuentan los sujetos. (Svampa, 2005, pp. 78-79)

Con la renuncia tácita a la idea del desarrollo social -equitativo, justo-, cuestiones como la desigualdad quedan completamente relegadas de la agenda pública del Estado, quizás mucho más interesado en mantener una frágil gobernabilidad -en una época en la que la dinámica del mercado apenas si le permite margen de acción- que en apostar por algún tipo de integración social incluyente. Es en este contexto en el que prevalecen criterios eficientistas de gestión, conformes a una racionalidad economicista e instrumental (Apel, 1989). Ello, más que ser un asunto meramente simbólico, ha significado el desmonte del Estado-nación de sus responsabilidades políticas relacionadas con la generación de condiciones de igualdad, justicia, inclusión social y solidaridad (Habermas, 2000).

La consecuencia de esta acentuada condición de orfandad de los nacionales es, en buena medida, la resistencia del ciudadano a ser apartado de los beneficios residuales que aún le ofrece el Estadonación. Pero, justamente, al ser estos cada vez más escasos, generan demandas parcializadas, las más de las veces mediante actuaciones sectarias. Esto que podría denominarse esencialismo cívico suele traducirse en discriminación, racismo, xenofobia o cualquier otra expresión de un nacionalismo vernáculo que se creía erradicado o atenuado, en principio, a partir de las políticas más progresistas de observancia y respeto de los derechos humanos universales, promovidos, especialmente, a través de las reformas constitucionales de las últimas décadas en los países de la región.

Cada vez más separada de fines sociales, comunales, incluyentes y solidarios, la nacionalidad se construye y define hoy en medio de un enorme mercado de bienes simbólicos y a partir de nuevas hegemonías supraestatales. Así, la emergencia de formas subalternas de habitar el mundo y de posicionar proyectos de vida individuales y colectivos por parte de comunidades indígenas, minorías étnicas 
históricamente excluidas, inmigrantes y sectores poblacionales crecientemente marginales, suele ser vista desde el nuevo imaginario social global deslocalizado como fenómeno curioso, "interesante", esto es, bajo la lente de un culturalismo superficial, un exotismo light que impide tomarse en serio toda exigencia de reconocimiento proveniente de dichos grupos. Así, opera un proceso de despolitización de la voz y las reivindicaciones de quienes marchan siempre por fuera de los centros de poder y las esferas de decisión política, en los bordes de la sociedad, aunque sus fronteras existenciales y habitacionales ya cubran la mayor parte de los territorios nacionales.

El imaginario social de la grandeza de la nación, reproducido en y desde la escuela, en relación con la idea de progreso vinculado al mundo del trabajo, el acceso a la educación formal a lo largo de la vida y a la movilidad social, no se encuentra clausurado del todo en la vida de estos jóvenes, pero es realmente un imaginario lejano de su cotidianidad, de su experiencia de todos los días.

Veamos ahora las representaciones gráficas que sobre la nación propia llevaron a cabo a cabo diecinueve chicos, pertenecientes a uno de los grupos con los que se adelantó el estudio. Consideramos que aquí aparece mucho menos la nación vinculada a la historia aprendida que los imaginarios de nación a partir de las vivencias cotidianas de los jóvenes, una relación inextricable entre lo tangible y lo posible.

Estas representaciones quizás puedan complementar, incluso contradecir, algunos de los hallazgos más relevantes arriba expuestos. Como es sabido, la imagen muchas veces dice cosas que la palabra oral o escrita no siempre logra expresar. Sin embargo, la pretensión original en este apartado del estudio ha sido contar con un recurso de apoyo a los relatos, una ilustración, mediante otros medios, de lo allí significado, mediante la cual los chicos también dan cuenta de la manera como viven su nación, de cómo construyen el tránsito de ida y regreso entre el aprendizaje de la historia y la experiencia de todos los días.
Figura 1. La nación propia según Noelia.

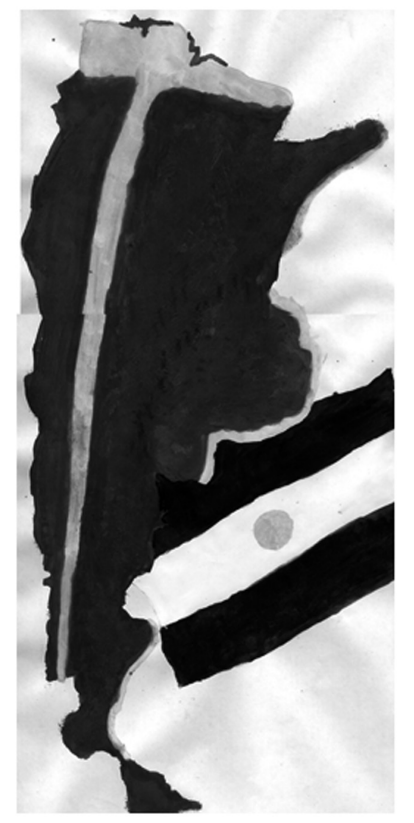

Noelia: Hice un mapa de Argentina en forma de bife, porque es algo muy de acá de los argentinos un buen bife, pero es como unos pocos se quieren comer la mejor parte y no dejar nada para los demás.

Figura 2. La nación propia según Gabriela G.

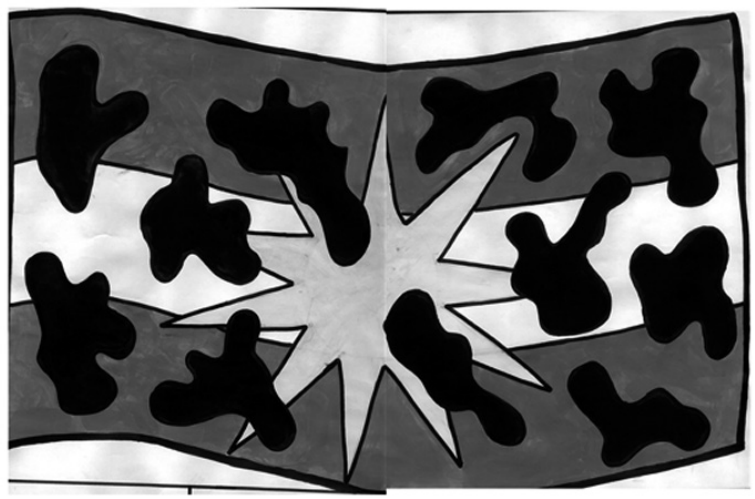

Gabriela G.: Yo quise expresar la nación con la bandera argentina. Esta representa a los argentinos. El sol es más grande, por el esfuerzo de cada una de las personas que habitan este suelo y las manchas negras representan los momentos malos y turbios que tuvo nuestro gobierno. 
Figura 3. La nación propia según Paola

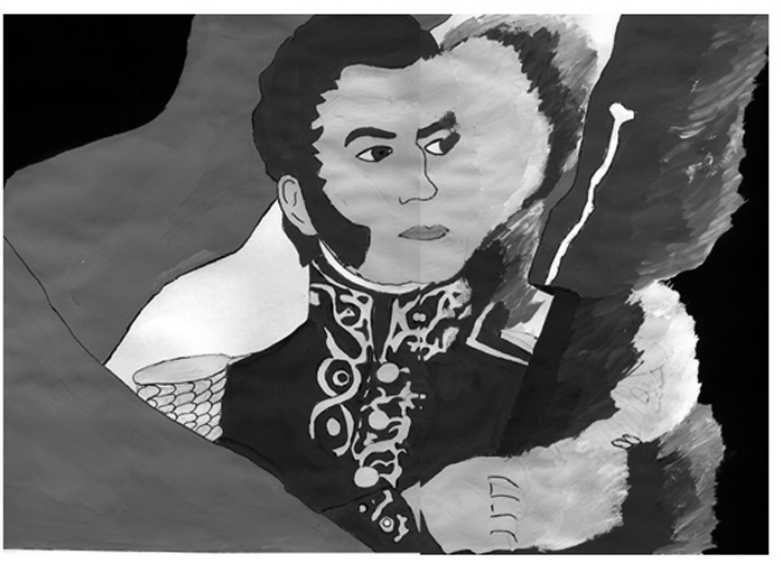

Paola: Lo que quise explicar en la pintura es que una nación se forja del pasado, o sea, la nación necesita una base para formarse. Si nosotros no respetamos a nuestro pasado en el sentido de olvidar los valores dados por nuestros próceres, no vamos a saber respetar nuestro presente y menos saber qué hacer con el futuro de nuestra nación. Y muestro que hoy en día puede ser que nos acordemos de nuestros grandes próceres, pero no rescatamos lo que ellos quisieron dejar como legado a nuestra nación. Por eso puse a San Martín, porque por más que sea el prócer que la mayoría de la gente recuerda, no se pudieron quedar sus valores: valentía, libertad, opinión propia, ideología propia, lucha ante los opresores, inteligencia, astucia y, sobre todo, amor a la nación.

Figura 4. La nación propia según Belén.

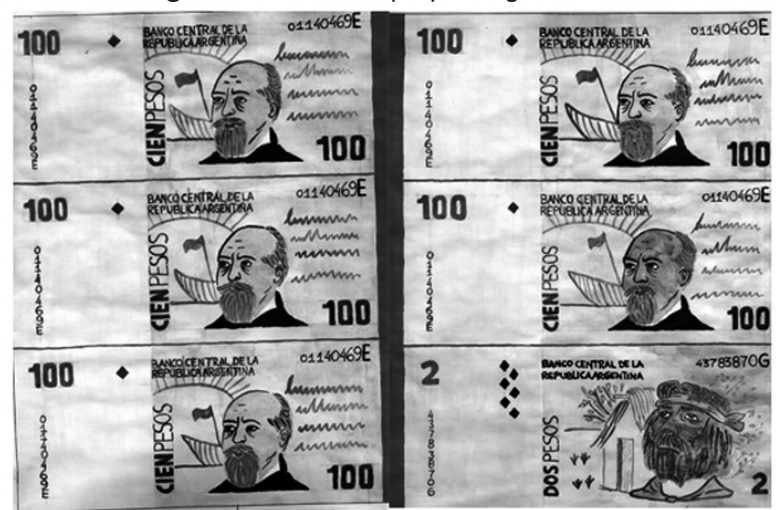

Belén: En mi dibujo yo critico la desvalorización del gobierno por todos los habitantes argentinos que consideran como un símbolo patrio a una persona (en este caso Roca) que hizo mucha maldad. No descarto que también hizo cosas buenas por este pueblo, pero lo consideran como símbolo a esta persona que para conseguir lo que quería pasó sobre todo y no le importó nada, y desvaloriza lo bueno del gaucho como un vago (que no es nada de eso). El gaucho solo buscaba y buscó la libertad.

Figura 5. La nación propia según Sonia

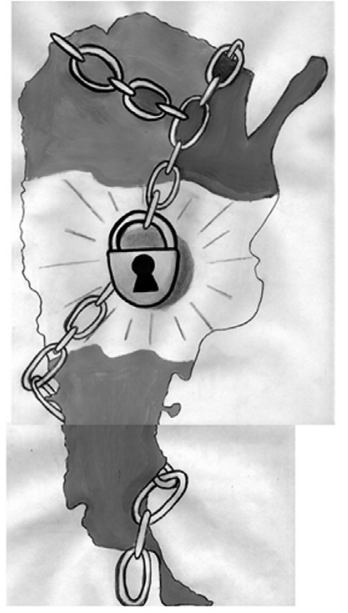

Sonia: Desde mi punto de vista la Argentina está perdiendo su libertad poco a poco, ya que pasó por distintos malos tratos. Las cadenas y el candado representan que la sociedad está presa de las cosas que disfrutaba anteriormente y cada vez depende de otros países.

Figura 6. La nación propia según Jessica.

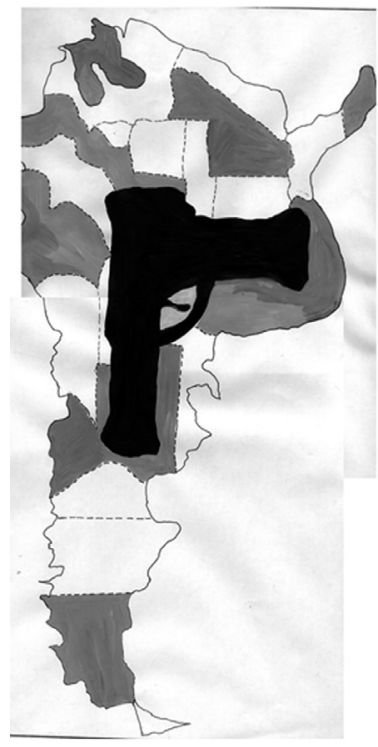

Jessica: Es la forma de representar la nación en este momento, la inseguridad nos ataca en cualquier momento y en cualquier parte del país. 
Figura 7. La nación propia según Daniela.

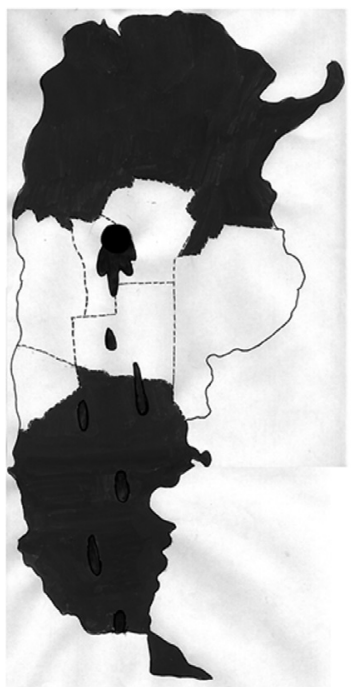

Daniela: Yo quise expresar la violencia, el maltrato en general, es decir, desde el gobierno hasta lo que está pasando en el mundo.

Figura 8. La nación propia según Soledad.

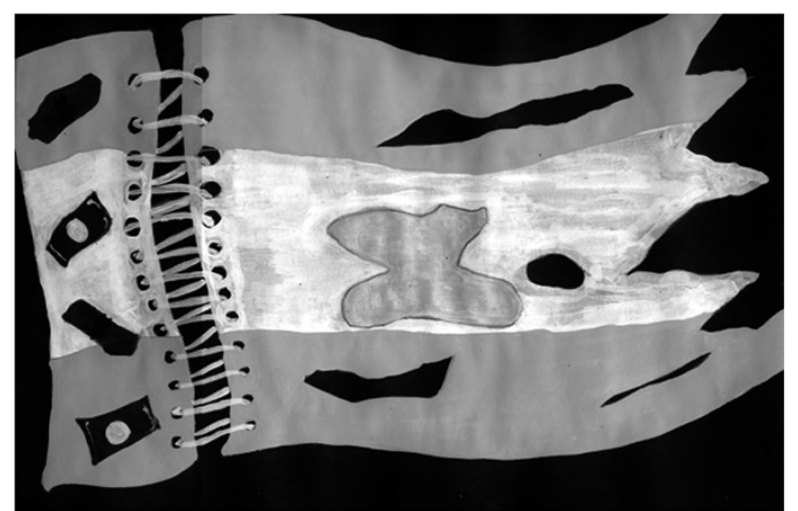

Soledad: Yo en este trabajo quise representar lo que sucede en nuestro país. La mayor parte es la pobreza: la parte de la bandera rota y más grande. $Y$ la menor parte: la riqueza. En esta bandera estos dos grupos se encuentran separados pero a su vez unidos por una costura, con esto quiero decir que la población de la riqueza no le da importancia a la pobreza, solo le importa la plata, pero aunque quieran separarse de este grupo no pueden porque representan y conforman un mismo país.
Figura 9. La nación propia según Daniel.

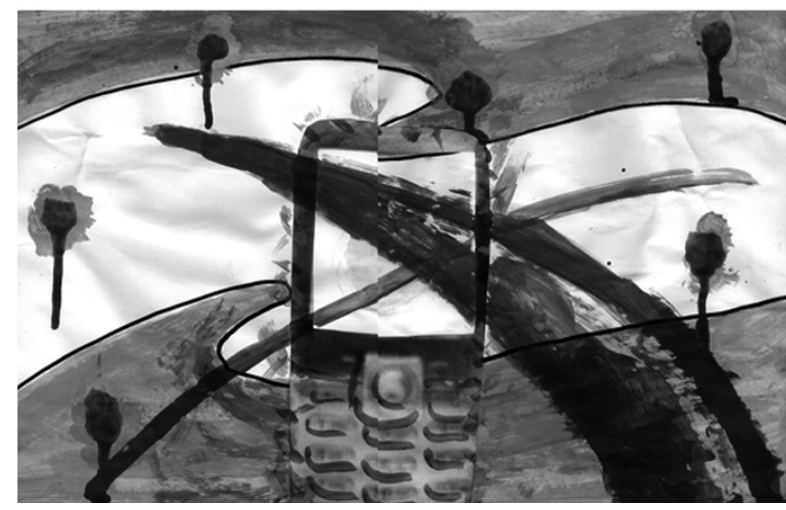

Daniel: Quiero representar el consumismo en nuestro país, la pérdida del amor a la Argentina, como se vive ahora el patriotismo.

Figura 10. La nación propia según Gastón.

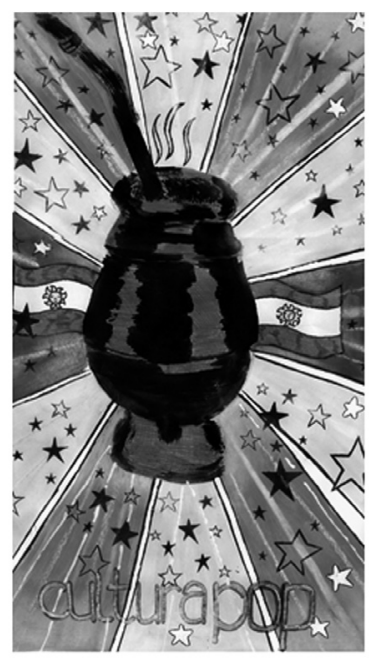

Gastón: Decidí hacer cultura nacional y como el mate, en mi punto de vista, es consumido por el $99 \%$ de la sociedad argentina, qué mejor que poderlo utilizar como imagen de este trabajo. Es por eso que decidí dibujarlo como una foto blanco y negro $\mathrm{y}$ en las partes blancas poner rosado, las estrellas y los rayos del sol como si tuviera brillo, estilo, magia. 
Figura 11. La nación propia según Melisa.

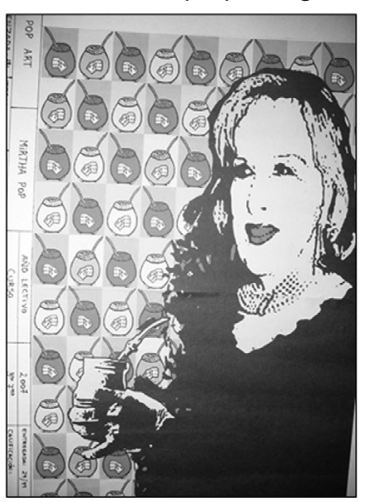

Melisa: Este trabajo representa el mate, muy importante para nosotros, con las banderitas de Argentina y a Mirta [conocida conductora de programas de televisión] tomando mate, como con un estilo muy pop, como una mezcla de cosas que la gente reconoce.

Figura 12. La nación propia según Cintia.

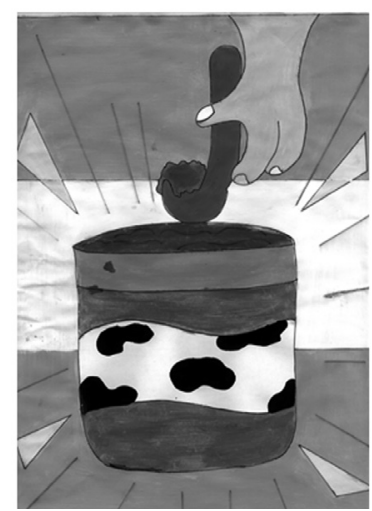

Cintia: Lo que quise expresar en mi dibujo es el orgullo por la Argentina y un ejemplo es el dulce de leche.

Figura 13. La nación propia según Florencia.

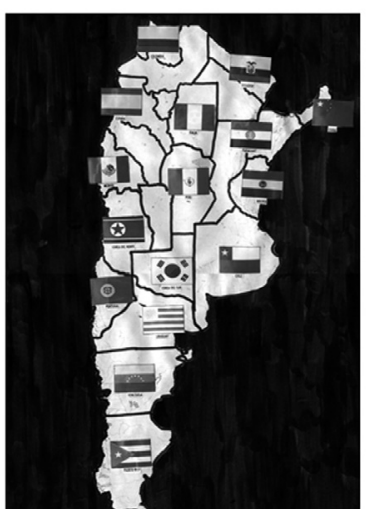

Florencia: Hice el mapa de Argentina con distintas banderas, refiriéndome a la diversidad que hay en Argentina, por la cantidad de extranjeros que habitan en nuestro país.

Figura 14. La nación propia según Carlos.

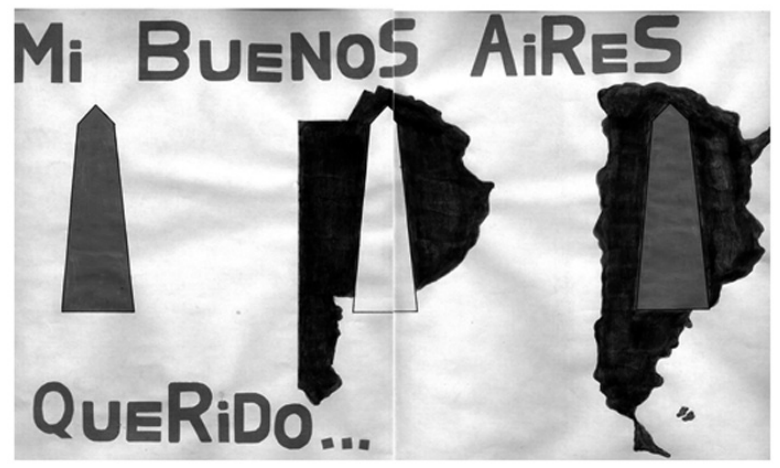

Carlos: Hice el obelisco porque es algo que representa a Argentina, vendría ser como lo que más se ve en la televisión y en todo cuando se pasa a Buenos Aires.

Figura 15. La nación propia según Christian

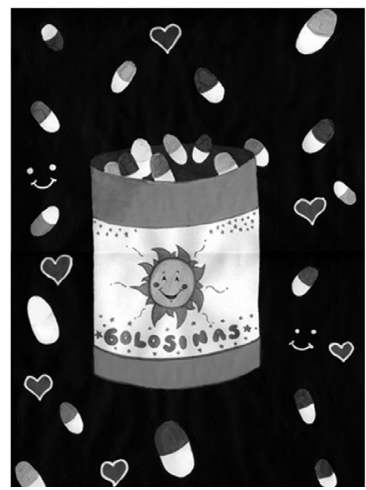

Christian: Lo que quise expresar es que en la Argentina las drogas son demasiado accesibles y que gran parte de los ciudadanos (mayormente los adolescentes) lo toman como si fuera algo común, que es divertido, como si fueran golosinas.

Figura 16. La nación propia según Sabrina.

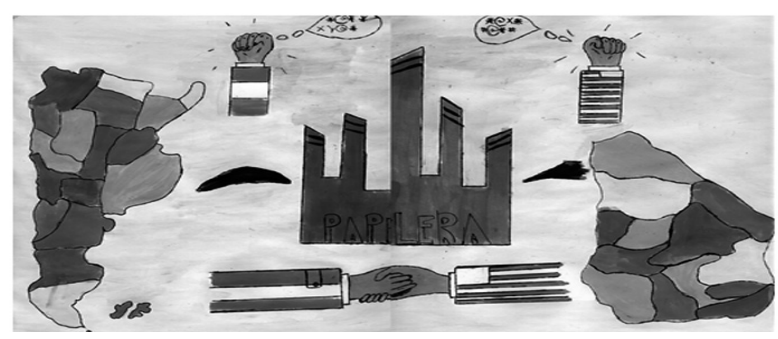


Sabrina: Quise representar el conflicto por las papeleras. Los presidentes se juntaron públicamente diciendo que todo se va a solucionar porque los países hermanos no se pelean. Mi crítica es hacia la falsedad entre los presidentes porque al verse públicamente se dan las manos y en mi opinión después hablan uno del otro a las espaldas, mintiendo, siendo los que tiene que dar ejemplo a la nación.

Figura 17. La nación propia según Néstor.

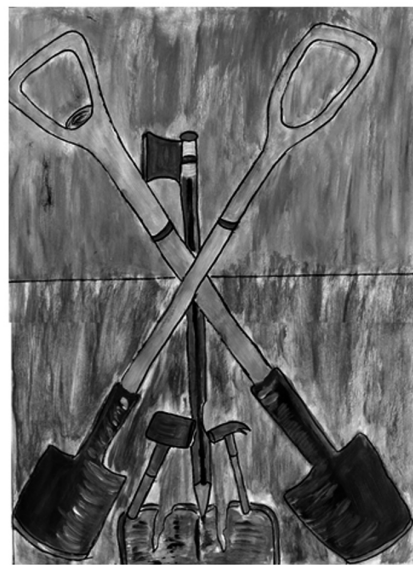

Néstor: Lo que quise representar es la crítica que hago acerca de que los jóvenes estudiantes dejan sus estudios y se ponen a trabajar. Por eso están las palas y los martillos que dañan al lápiz, que no dejan seguir estudiando.

Figura 18. La nación propia según Norma.

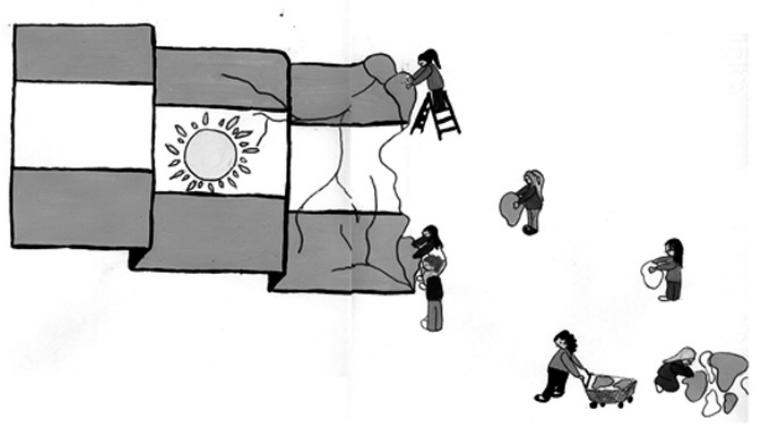

Norma: La imagen de nación está representada de la siguiente manera: con sus quebraduras y sus partes que le faltan, es porque la nación después de las cosas que le pasaron: guerras, golpes de Estado, mal manejo de la política y todo, se fue poco a poco destruyendo y las personas que se ven en el dibujo representan a la sociedad que quiere, desde mi punto de vista, tratar de mejorar lo que se perdió.

Figura 19. La nación propia según Lucas.

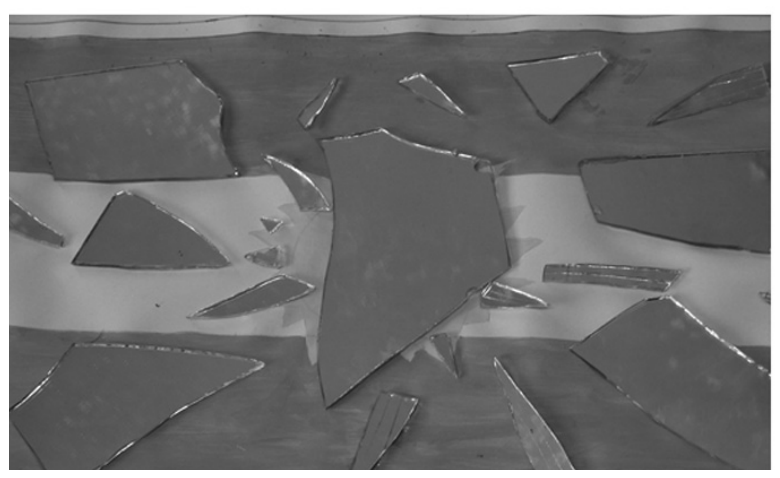

Lucas: El trabajo representa todos los problemas que tuvo el país, como se quebró. Pero si uno se da cuenta en esos pedazos de espejo uno ve lo que quiere ver, ve cosas buenas o malas, porque en este espejo se refleja Argentina, o sea, nosotros. Tratemos de que siempre se refleje lo bueno.

Las biografías de los jóvenes, sus historias cotidianas, son asumidas aquí como historias sin posibilidad de cambio radical, como pasados que han tenido que trasegar los efectos particularmente negativos de lo que es y ha sido siempre determinado por otros.

Recuperar y discutir con los estudiantes nuestros-sus- propios relatos sobre la relación entre la nación aprendida y la nación vivida, sus imaginarios y aprendizajes, puede resultar una alternativa pedagógica interesante, no solo en dirección a una mejor comprensión de la historia en la escuela, sino también como forma de resistencia a todo lo que ideológicamente persiste en ser naturalizado. La imagen de la nación propia como el mapa y el espejo fragmentado de la ilustración de Lucas resulta muy sugerente como invitación a imaginar la nación, al tiempo, desde la potencial unión de sus pedazos, como en lo que refleja, de manera independiente, cada una de sus partes.

\section{Consideraciones finales}

Los relatos de nación conjugan elementos de carácter cognitivo, afectivo, moral y político. Aunque en ocasiones los procesos de enseñanza de las ciencias sociales y la historia y las experiencias de investigación 
suelen privilegiar uno de estos elementos sobre los otros (p.ej., el cognitivo sobre los demás), su configuración depende de la articulación de todos ellos.

Como pudo notarse, la complejidad y riqueza de los relatos de nación está relacionada, además, con: a) el desarrollo de posturas críticas frente a la historia aprendida y por aprender, b) la capacidad de justificar posturas morales subyacentes a dichos aprendizajes y c) la capacidad de extraer orientaciones prácticas para la vida, esto es, para el presente y para el futuro.

La comprensión de contenidos históricos por parte de los jóvenes actores de este estudio, que personifican una condición socioeconómica de exclusión, no es anecdótica o superficial, es sumamente compleja en términos de las implicaciones éticas y políticas que los chicos de allí derivan. Se ha señalado que las ideas y creencias que las personas construyen sobre su propia nación tienen una fuerte capacidad de cohesión simbólica y social (Anderson, 1983; Hobsbawn, 1990; Gellner, 1993; Margalit, 1997; McKim, 1997; Carretero, 2007; Seixas, 2007, entre otros). Tal efecto se presenta de manera particularmente intensa en estos jóvenes, a diferencia de otros sectores poblacionales, aunque pueda resultar paradójico si se tiene en cuenta que no reciben casi nada de su Estado-nación. Ello se explicaría a partir de un intento de resolver una necesidad de integración, al menos simbólica, al constructo nosotros nación. En buena medida, debido, igualmente, a eficacia de los procesos de identificación que promueve la enseñanza de la historia en la escuela.

La manera como se construyen significados de nación en la escuela, en contextos de marginalidad, propicia en los jóvenes ideas particularmente defensivas de nación, nacionalidad y ciudadanía, lo cual tiene consecuencias en términos de dificultar o impedir que los sujetos establezcan relaciones propositivas y vinculantes de las esferas personal, social y política en sus vidas cotidianas y en relación con sus expectativas de futuro en la sociedad nacional de la que hacen parte.

Las ideas defensivas de nación y ciudadanía se relacionan, además, con un tipo de aprendizaje de la historia que simplifica los acontecimientos históricos y el rol de sus actores a un esquema dicotómico: héroe-villano; opresor-oprimido; buenos-malos; vencedores-vencidos. Dichos esquemas contribuirían a su vez, en estos actores, a la naturalización de relaciones inclusión-exclusión y a su pasiva legitimación. Esta forma de aprendizaje de la historia, señalan algunos investigadores (Gergen, 2005; VanSledright, 2008) contribuye a la reproducción simbólica de relaciones de dominación, postergando o suspendiendo indefinidamente cualquier pretensión o iniciativa de justicia social y equidad. Aunque tales ideas defensivas no estarían presentes de manera exclusiva en este tipo de grupos sociales, probablemente sea en él donde mayor impacto social alcanzan, dada la tendencia a la aceptación pasiva que generan entre las personas.

El imaginario de nación que emerge de la estructura moderna del Estado-nación es el resultado de la complementariedad de las ideas de defensa y proyecto. En su orden, lo que se considera necesario conservar es: historia común, identidad nacional, cultura política; y lo que se requiere promover y desarrollar a futuro: ideales de progreso, destino compartido, justicia social. Estos elementos, uno de carácter conservadurista y otro progresista, se mantienen en permanente tensión. Un horizonte ético-político en la nación por construir es una idea verdaderamente fecunda si mantiene y actualiza las demandas de justicia social, primero al interior de ese nosotros escindido y luego, en el camino hacia una figuración no amenazante del ellos simbólico requerido en la propia definición.

Si las naciones, o mejor sería decir los estados nacionales, tienen aún algo que ofrecer a sus ciudadanos en términos identitarios, más allá de los elementos simbólicos para el establecimiento y mantenimiento de la diferenciación nosotros-ellos, esto ha de pasar por la generación de instrumentos para la comprensión de la historia de dicho proceso, lo que por supuesto atañe de manera relevante al mundo de la escuela, a los contenidos que allí circulan, a las mediaciones pedagógicas empleadas $\mathrm{y}$ a las orientaciones morales que le dan sustento. 


\section{Referencias}

Anderson, B. (1983). Imagined Communities. Reflections on the Origin and Spread of Nationalism. Londres: Verso. [Ed. cast.: Anderson, B. (2006). Comunidades imaginadas. Reflexiones sobre el origen y la difusión del nacionalismo. México: Fondo de Cultura Económica.]

Apel, K. (1989). La situación del hombre como problema ético. En X. Palacios y F. Jarauta (Eds.), Razón, ética y política. Barcelona: Anthropos.

Barton, K. \& Levstik, L. (2004). Teaching History for the Common Good. New Jersey: Earlbaum.

Carretero, M. (2007). Documentos de identidad. La construcción de la memoria histórica en un mundo global. Buenos Aires: Paidós.

Gellner, E. (1993). Nations and Nationalism. Ithaca, NY: Cornell University Press.

Gergen, K. (2005). Narrative, Moral Identity, and Historical Consciousness. In J. Straub (Ed.), Narration, Identity, and Historical Consciousness. New YorkOxford: Berghahn Books.

Habermas, J. (2000). La constelación posnacional. Ensayos políticos. Barcelona: Paidós.

Hobsbawn, E. (1990). Nations and Nationalism since 1780. Programme, Myth, Reality. [Ed. cast.: Hobsbawn, E. (2004). Naciones y nacionalismo desde 1780. Barcelona: Crítica.]

Kriger, M. (2007). Historia, identidad y proyecto. Un estudio de las representaciones de los jóvenes argentinos sobre el pasado, presente y futuro de la nación. Tesis. Doctorado en Ciencias Sociales. Facultad Latinoamericana de Ciencias Sociales FLACSO -Sede Académica Argentina-.

Margalit, A. (1997). The Moral Psychology of Nationalism. In R. McKim \& J. McMahan (Eds.), The Morality of Nationalism, Vol. 1. Oxford: Oxford University Press. [Ed. cast.: Margalit, A. (2003). La psicología moral del nacionalismo. En La moral del nacionalismo, Vol. 1. Barcelona: Gedisa.]

McKim, R. (1997). National Identity and Respect among Nations. In R. McKim \& J. McMahan (Eds.), The Morality of Nationalism, Vol. 2. Oxford: Oxford University Press. [Ed. cast.: McKim, R. (2003). La identidad nacional y el respeto entre las naciones. En La moral del nacionalismo, Vol. 2. Barcelona: Gedisa.]
Ricoeur, P. (1985). Temps et récit (T. 3: Le temps raconté). Paris: Éditions du Seuil. [Ed. cast.: Ricoeur, P. (2006). Tiempo y narración (Tomo 3: El tiempo narrado). México: Siglo XXI.]

Ricoeur, P. (2000). La Memoire, l histoire, l oubli. Paris: Éditions du Seuil. [Ed. cast.: Ricoeur, P. (2003). La memoria, la historia, el olvido. Madrid: Trotta.]

Ruiz, A. (2009). La nación en los márgenes. Estudio de los elementos de carácter representacional, moral y político en relatos de nación de jóvenes de últimos grados de secundaria, de una escuela pública, en el conurbano bonaerense. Tesis Doctoral. Doctorado en ciencias sociales. Facultad Latinoamericana de Ciencias Sociales FLACSO -Argentina-.

Ruiz, A. (2011). Nación, moral y narración. Imaginarios sociales en la enseñanza y el aprendizaje de la historia. Buenos Aires: Miño y Dávila.

Rüsen, J. (1999). El desarrollo de la competencia narrativa en el aprendizaje histórico. Una hipótesis ontogenética relativa a la conciencia moral. En Revista Propuesta Educativa, 7, 27-36. (Buenos Aires: Facultad Latinoamericana de Ciencias Sociales).

Rüsen, J. (2001). A constituiçao narrativa do sentido histórico (Apéndice à ediçao brasileira). En Razao histórica. Teoria da história: os fundamentos da ciencia histórica. Brasília: Editora Universidade de Brasília.

Rüsen, J. (2005). History: Narration -InterpretationOrientation. New York: Berghahn Books.

Seixas, P. (2005). Historical Consciousness: The Progress of Knowledge in a Postprogressive Age. In J. Straub (Ed.), Narration, Identity, and Historical Consciousness. New York-Oxford: Berghahn Books.

Seixas, P. (2007). Who Needs a Canon? In M. Grever \& S. Stuurman (Eds.), Beyond the Canon. History for Twenty-first Century. New York: Palgrave MacMillan.

Svampa, M. (2005). La sociedad excluyente. La Argentina bajo el signo del neoliberalismo. Buenos Aires: Taurus.

Todorov, T. (1991). Les morales de l'histoire. Paris: Bernard Grasset. [Ed. cast.: Todorov, T. (1993). Las morales de la historia. Barcelona: Paidós.]

Todorov, T. (1995). Les abus de la mémoire. Paris: Arléa. [Ed. cast.: Todorov, T. (2000). Los abusos de la memoria. Barcelona: Paidós.] 
Van Sledright, B. (2008). Narratives of Nation-State, Historical Knowledge, and School History Education. In Review of Research in Education, Vol. 32, 109-146.

Von Borries, B. (1994). (Re-)Constructing History and Moral Judgment: On Relationships Between Interpretations of the Past and Perceptions of the Present. In M. Carretero \& J. Voss (Eds.), Cognitive and Instructional Processes in History and the Social Sciences (pp. 339-356). Hillsdale-New York: Erlbaum.

White, H. (2003). Hecho y figuración en el discurso histórico. En El texto histórico como artefacto literario. Barcelona: Paidós. 